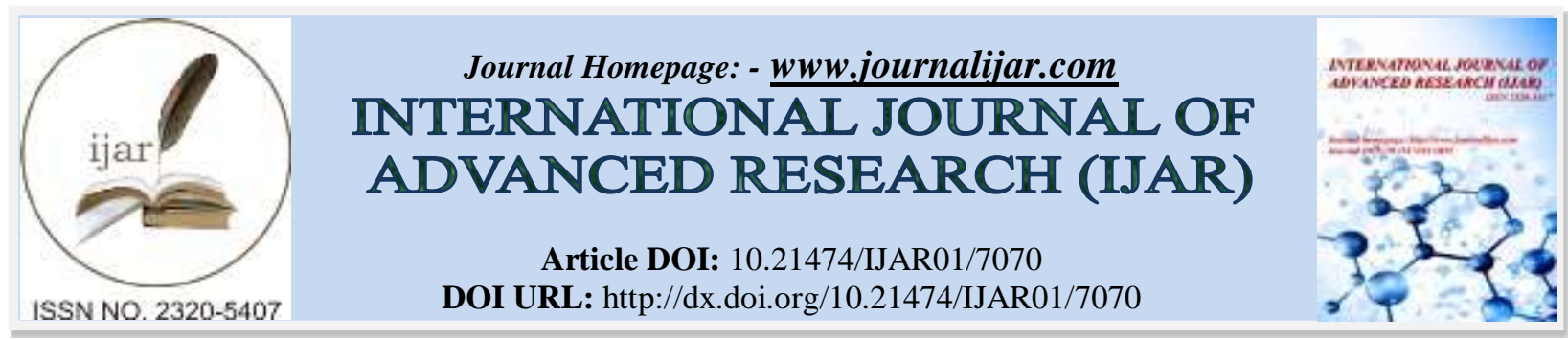

RESEARCH ARTICLE

\title{
"DIFFERENTIATED INSTRUCTION THROUGH FLEXIBLE GROUPING: STRATEGY TO ENHANCE THE LERANERS' ACADEMIC PERFORMANCE IN DISCIPLINE AND IDEAS IN SOCIAL SCIENCES (DISS)".
}

\section{Margie Simangan Balungaya.}

Cagayan National High School-Senior High School, San Gabriel, Tuguegarao City.

\section{Manuscript Info}

Manuscript History

Received: 10 March 2018

Final Accepted: 12 April 2018

Published: May 2018

Keywords:-

Differentiated Instruction, Flexible

Grouping, Academic Performance.

\begin{abstract}
This study aimed to determine the effectiveness of differentiated instruction through flexible grouping in enhancing the learners' academic performance in Discipline and Ideas in Social Sciences (DISS). A quasi-experimental research design was used in which two different learning environments were compared. The participants of the study were two classes of Senior High School students enrolled in DISS, assigned randomly as experimental and control groups. Participants in both groups were identified and matched based on their grade point average (GPA). The control group was taught using the traditional approach of teaching while the experimental group was taught the same lesson using differentiated instruction through flexible grouping. The effectiveness of the differentiated instruction was measured through the pre-test and post-test performances of the participants. The results of this study revealed that the use of flexible grouping improves students' academic performance. The strategy enhances the ability of students to make better in class performance. Furthermore, it confirmed the concept of differentiated strategy as a method in which students learn better when they are given varied ways in doing class activities. It also develops among students social values such as unity and cooperation.
\end{abstract}

Copy Right, IJAR, 2018,. All rights reserved.

\section{Context And Rationale:-}

In today's classrooms, educators have learned that students learn best when they are taught in their own unique style and ability. Being a $21^{\text {st }}$ century educator means the ability to be able to teach and reach all learners (Marzano,2010). That means the ability to differentiate learning so that all students are able to learn using their own unique style and/or by their ability or readiness level (Tomlinson, 2006).

In response to the challenges of the $21^{\text {st }}$ century particularly in the academe, the $\mathrm{K}$ to 12 Basic Education Curriculum was rolled out in 2016 in the Philippines. The curriculum aims that learners are given an opportunity to build upon their prior knowledge while utilizing their own skills, interest, styles and talents (K to 12 Curriculum Guide).

One of the subjects taught is Discipline and Ideas in Social Sciences (DISS) which includes the Indigenizing of Social Sciences. The subject aims that students be able to demonstrate an understanding of the key concepts in the Social Sciences rooted in Filipino language/s and experiences and to carry out an exploration of personal and social 
experiences using indigenous people. It also aims to evaluate the person's personality using the core values of Filipino Psychology.

With the kind of adolescents now, teachers find it interesting to sustain their interest in learning Social Sciences. The nature of the subject calls for varied activities and learning platforms which enhance learning. Innovative classroom strategies are planned and executed so as to enhance participation and assessment in learning.

The use of varied ways in learning has been proven to be effective and engaging in enhancing classroom performance particularly in learning Social Sciences. The use of differentiated instruction has been found in earlier studies to be one of the strategies highly useful in increasing students' engagement in learning.

The strategy stresses the need to consider the preferred style of students in doing group activity. The teacher's role is to provide these learning experiences in the teaching of Social Sciences and try to plan the use of the strategy so that students will be directed and eventually will greatly benefit from this kind of strategy.

The teacher's flexibility is enclosed particularly in teaching different kinds of learners with different intellectual capacities, talents or skills, interest and learning styles especially in heterogeneous groupings of learners. This learning situation call for teachers to create lesson for all learners based upon their readiness, interests and background knowledge. It is important to look at a new approach that may increase student participation, selfconcept and meet the needs of a diverse learner. De Jesus (2012) noted that it is imperative not to exclude any child in the classroom, so a differentiated instruction through flexible grouping must be provided by a teacher.

\section{Innovation, Intervention, And Strategy:-}

This study aimed to determine the effectiveness of differentiated instruction through flexible grouping in enhancing the learners' academic performance in Discipline and Ideas in Social Sciences (DISS).

A quasi-experimental research design was used in which two different learning environments were compared. The participants of the study were two classes of Senior High School students enrolled in DISS. One class was assigned randomly as experimental group and the other as control group. Participants in both groupswere identified and matched based on their grade point average (GPA) in their previous subjects.

The experimental group was taught using differentiated instruction through flexible grouping. The students were grouped and regrouped throughout the period. The grouping varied from partners or dyads, rotating trio and small group.On the other hand, the control group was taught the same lesson using the traditional approach of teaching. The whole class have experienced the same mode of learning.

The aim of the strategy is to provide the students to experience learning collaboratively and at the same time learning from their peers. With this method, students will have the opportunity to work with, and learn from their peers in a way that they feel comfortable in contributing their knowledge (Gregory, 2013). When students work in a variety of groups, they learn to work independently and cooperatively with a variety of personalities (Hamdan, 2012).

Before the conduct of the strategy, the following steps were considered by the researcher:

- Selected the best type of configuration to meet the learning outcome for the activity.

- Evaluated all assessment data and looked over student-learning profiles to help them form the group.

- Created a color-coded system or chart to help the teacher and students know which group they are in.

- Gave specific instruction about the tasks groups must perform.

- Posted written instructions and expectations so the teacher don't have to repeat.

- Demonstrated routines and procedures for getting into and out of groups.

- Set specific time limit for students to complete their group work.

Types of flexible grouping conducted:

- Partners/dyads (two students)

- Triads (three students)

- Small groups (six students) 


\section{Research Questions:-}

1. What is the level of performance of the respondents in the pre-test?

2. What is the level of performance of the respondents in the post- test?

3. Is there a significant difference between the pre-test and post- test performances of the experimental and control groups after the experimentation?

\section{Methodology:-}

\section{a. Sources of Data}

The data were collected from the assessment of student-learning profiles. Other data were taken from the pre-test and post-test scores. Also from the result of the given group of activities and evaluation regarding the lesson discussed. The respondents of the study were the Grade I2 students particularly the last two sections (GAS Blocks 3 and 4) during the 2nd semester of school year 2017-2018.

\section{b. Data gathering Method}

The effectiveness of the differentiated instruction was measured through the pre-test and post-test performances of the participants. Pre-test was conducted before the intervention and after which the similar test was also conducted after the intervention which is the Post-test.

\section{c.Ethical Issues}

The researcher sought first the approval from the proper authority and the parents of the concerned students. All data that were gathered from the pre-test and post-test scores of Grade 12 students (GAS Blocks 3 and 4) who served as the respondents of this study was treated with foremost confidentiality.

\section{d. Plan forData Analysis}

The study made use of the quasi-experimental research design specifically the Pre-Test-Post Test control group design. The data gathered were analyzed using descriptive statistics such as frequency count and mean to describe the pre-test and post-test performances of the participants in both groups. The t-test for Independent Samples was used to compare the pre-test and post-test performances of the experimental group and control group.

\section{Results And Discussion:-}

Figure 1:- Pre-Test Performances of the Experimental and Control Groups

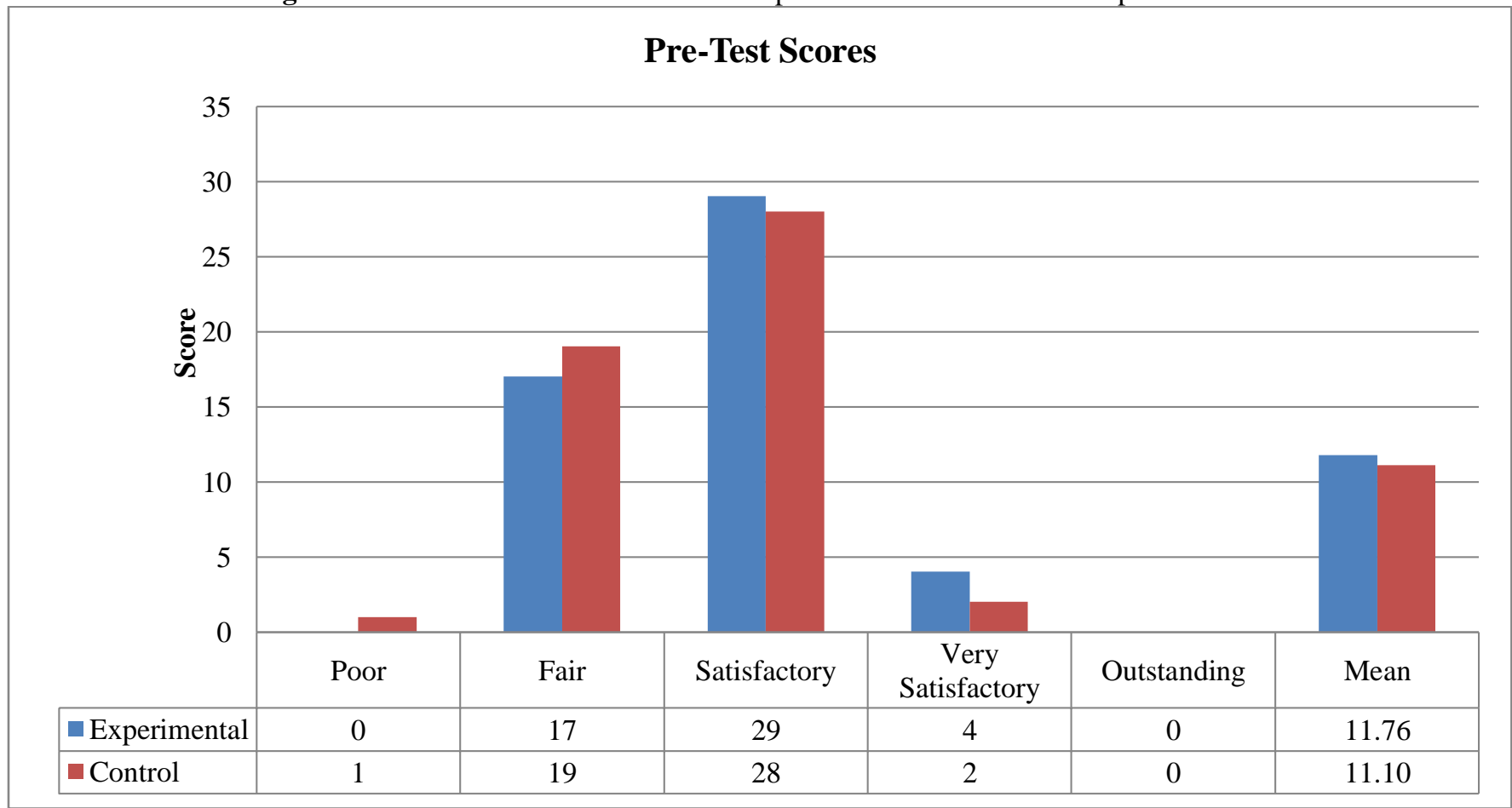


Figure 1 presents the pre-test performances of the participants from the experimental and control group. As reflected in the table, majority of the students in both groups have pre-test scores ranging from 11-15. This result indicates that they performed satisfactorily in the pre-test. The figure also reveals that the pre-test mean scores of experimental and control groups are nearly equal which means both groups have satisfactory performance before the conduct of the study.

Figure 2:- Post-Test Performances of Experimental and Control Groups

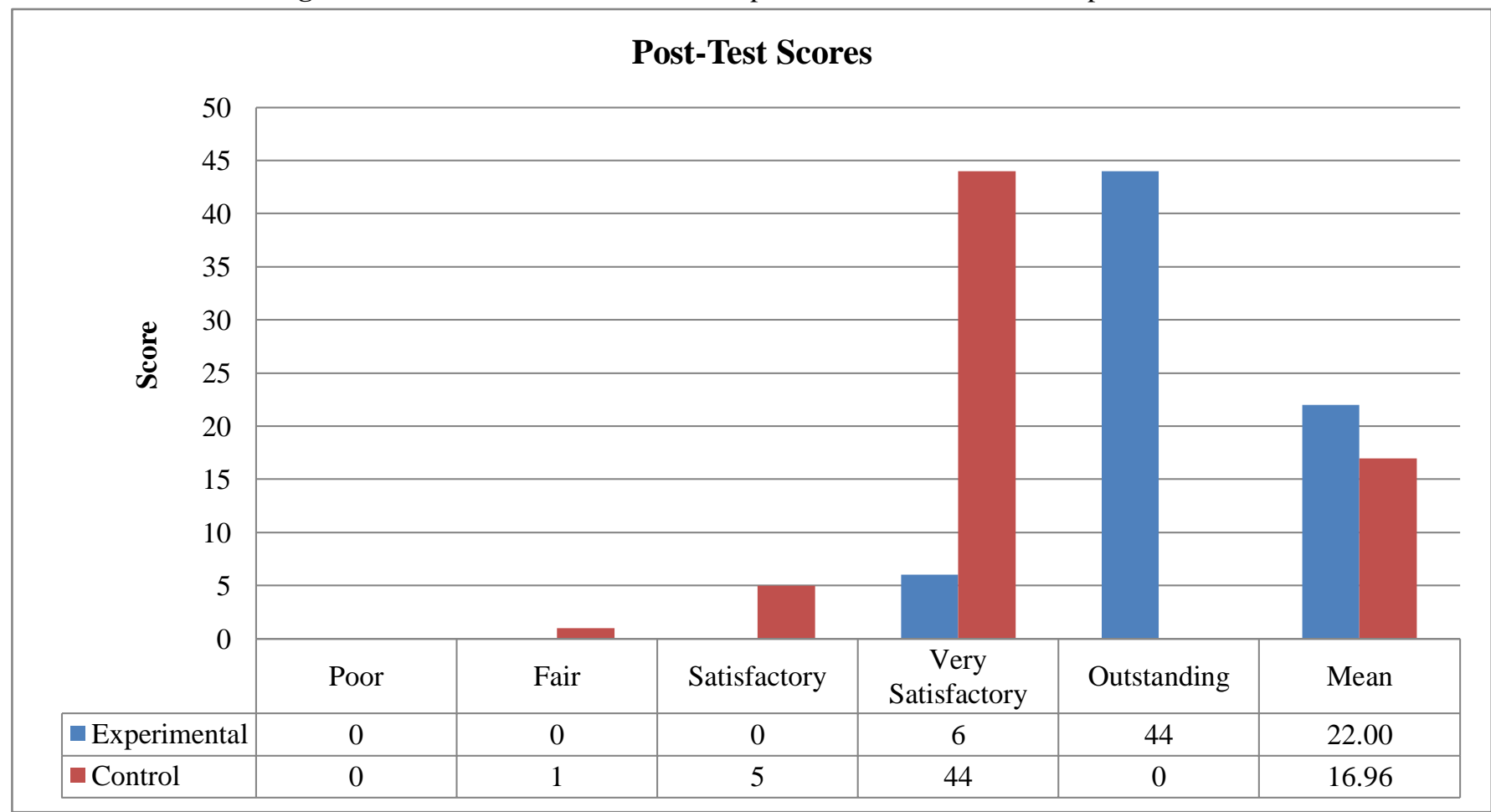

Figure 2presents the post-test performances of the participants from the experimental and control group. It could be seen from the table that the mean score of the experimental group is higher than the control group. It further reveals that $88 \%$ of the students in the experimental group have outstanding performance as compared to that of the control group. This implies that the use of the flexible grouping has improved the academic performance of the students.

Table 3:- Significant Difference in the Pretest and Posttest Performances of the Experimental and Control Groups

\begin{tabular}{|c|l|c|c|c|c|c|}
\hline Test & Group & Mean & $\begin{array}{c}\text { Mean } \\
\text { Difference }\end{array}$ & t-value & $\mathrm{p}$-value & Interpretation \\
\hline \multirow{2}{*}{ Pretest } & Experimental & 11.76 & 0.66 & 1.221 & .225 & Not Significant \\
\cline { 2 - 5 } & Control & 11.10 & & & & Significant \\
\hline \multirow{2}{*}{ Posttest } & Experimental & 22.00 & 5.04 & 15.356 & .000 & \\
\cline { 2 - 4 } & Control & 16.96 & & & & \\
\hline
\end{tabular}

As shown in the table, there is no statistically significant difference between the pre-test mean scores of the experimental and control groups. This implies that the two groups have comparable mental and social ability prior to the conduct of the study

The post-test mean score of the two groups reveals statistically significant difference. The t-value of 15.356 and pvalue of .000 indicates that the post-test performances of the experimental and control groups differ significantly. The result implies that the integration of flexible grouping in the teaching and learning of Discipline and Ideas in Social Sciences (DISS) is more effective than the traditional lecture method. 


\section{Conclusions and Recommendations:-}

A. Conclusions:

With the results of this study, it is confirmed that the use of flexible grouping improves learners' academic performance. The strategy enhances the ability of students to make better in class performance. Furthermore, it validates the concept of differentiated strategy as a method in which students learn better when they are given varied ways in doing class activities. It also develops among students' social values such as unity and cooperation as revealed in the results of the study.

\section{B. Recommendations:}

- The study may be replicated in other areas of concentration to prove the researchers' claim.

- The Social Science teachers be inspired to use the same Differentiated Instruction strategy in teaching. The strategy can be adopted in measuring the students' academic performance and other forms of assessment.

- Teachers in other grade levels of Secondary Education should have more resources and additional time for collaboration with their peers to share their practical knowledge about Differentiated Instruction strategies.

- The SDO Tuguegarao Cityshould continue to provide more support for educators to find opportunities to stimulate discourse about effective Differentiated Instruction strategies. 